Trinity University

Digital Commons@ Trinity

Biology Faculty Research

Biology Department

2019

\title{
Macroevolutionary Patterning in Glucocorticoids Suggests Different Selective Pressures Shape Baseline and Stress-Induced Levels
}

Maren N. Vitousek

Michele A. Johnson

Trinity University, mjohnso9@trinity.edu

C. J. Downs

E. T. Miller

L. B. Martin

See next page for additional authors

Follow this and additional works at: https://digitalcommons.trinity.edu/bio_faculty

Part of the Biology Commons

\section{Repository Citation}

Vitousek, M.N., Johnson, M.A., Downs, C.J., Miller, E.T., Martin, L.B., Francis, C.D., Donald, J.W., ... Williams, T.D. (2019).

Macroevolutionary patterning in glucocorticoids suggests different selective pressures shape baseline and stress-induced levels. The

American Naturalist, 193(6), 866-880. doi: 10.1086/703112

This Article is brought to you for free and open access by the Biology Department at Digital Commons @ Trinity. It has been accepted for inclusion in Biology Faculty Research by an authorized administrator of Digital Commons @ Trinity. For more information, please contact jcostanz@trinity.edu. 
Authors

Maren N. Vitousek, Michele A. Johnson, C. J. Downs, E. T. Miller, L. B. Martin, C. D. Francis, Jeremy W. Donald, M. J. Fuxjager, W. Goymann, M. Hau, Jerry F. Husak, Bonnie K. Kircher, R. Knapp, L. A. Schoenle, and T. D. Williams 


\title{
Macroevolutionary Patterning in Glucocorticoids Suggests Different Selective Pressures Shape Baseline and Stress-Induced Levels
}

\author{
Maren N. Vitousek, ${ }^{1,2, \star}$ Michele A. Johnson, ${ }^{3}$ Cynthia J. Downs, ${ }^{4}$ Eliot T. Miller, ${ }^{2}$ Lynn B. Martin, ${ }^{5}$ \\ Clinton D. Francis, ${ }^{6}$ Jeremy W. Donald, ${ }^{7, \dagger}$ Matthew J. Fuxjager, ${ }^{8, \dagger}$ Wolfgang Goymann, ${ }^{9, \dagger}$ \\ Michaela Hau, ${ }^{9,10, \dagger}$ Jerry F. Husak, ${ }^{11, \dagger}$ Bonnie K. Kircher, ${ }^{12, \dagger}$ Rosemary Knapp, ${ }^{13, \dagger}$ \\ Laura A. Schoenle, ${ }^{4,5} \uparrow$ and Tony D. Williams ${ }^{14, \dagger}$
}

1. Department of Ecology and Evolutionary Biology, Cornell University, Ithaca, New York 14853; 2. Cornell Lab of Ornithology, Ithaca, New York 14850; 3. Department of Biology, Trinity University, San Antonio, Texas 78212; 4. Department of Biology, Hamilton College, Clinton, New York 13323; 5. Department of Global Health, University of South Florida, Tampa, Florida 33620; 6. Department of Biological Sciences, California Polytechnic State University, San Luis Obispo, California 93407; 7. Coates Library, Trinity University, San Antonio, Texas 78212; 8. Department of Biology, Wake Forest University, Winston-Salem, North Carolina 27109; 9. Max Planck Institute for Ornithology, Seewiesen 82319, Germany; 10. Department of Biology, University of Konstanz, Konstanz 78457, Germany; 11. Department of Biology, University of St. Thomas, St. Paul, Minnesota 55105; 12. Department of Biology, University of Florida, Gainesville, Florida 32608; 13. Department of Biology, University of Oklahoma, Norman, Oklahoma 73019; 14. Department of Biological Sciences, Simon Fraser University, Burnaby, British Columbia V5A 1S6, Canada

Submitted June 16, 2018; Accepted December 18, 2018; Electronically published April 17, 2019

Online enhancements: appendix figures and table. Dryad data: https://dx.doi.org/10.5061/dryad.th03671.

\begin{abstract}
Aвstract: Glucocorticoid (GC) hormones are important phenotypic mediators across vertebrates, but their circulating concentrations can vary markedly. Here we investigate macroevolutionary patterning in GC levels across tetrapods by testing seven specific hypotheses about GC variation and evaluating whether the supported hypotheses reveal consistent patterns in GC evolution. If selection generally favors the "supportive" role of GCs in responding effectively to challenges, then baseline and/or stress-induced GCs may be higher in challenging contexts. Alternatively, if selection generally favors "protection" from GCinduced costs, GCs may be lower in environments where challenges are more common or severe. The predictors of baseline GCs were all consistent with supportive effects: levels were higher in smaller organisms and in those inhabiting more energetically demanding environments. During breeding, baseline GCs were also higher in populations and species with fewer lifetime opportunities to reproduce. The predictors of stress-induced GCs were instead more consistent with the protection hypothesis: during breeding, levels were lower in organisms with fewer lifetime reproductive opportunities. Overall, these patterns indicate a surprising degree of consistency in how some selective pressures shape GCs across broad taxonomic scales; at the same time, in challenging en-

* Corresponding author; email: mnv6@cornell.edu.

${ }^{\dagger}$ These authors are listed in alphabetical order.

ORCIDs: Vitousek, https://orcid.org/0000-0003-2855-0832; Johnson, https:// orcid.org/0000-0002-9278-5639; Martin, https://orcid.org/0000-0002-5887-4937; Donald, https://orcid.org/0000-0002-1997-0619; Hau, https://orcid.org/0000-0002 -3836-4083; Knapp, https://orcid.org/0000-0001-6923-8410; Schoenle, https://orcid .org/0000-0002-9591-1194.

Am. Nat. 2019. Vol. 193, pp. 866-880. () 2019 by The University of Chicago. 0003-0147/2019/19306-58550\$15.00. All rights reserved.

DOI: $10.1086 / 703112$
\end{abstract}

vironments selection appears to operate on baseline and stress-induced GCs in distinct ways.

Keywords: stress, comparative physiology, cortisol, corticosterone, steroid, evolutionary endocrinology.

\section{Introduction}

Glucocorticoid (GC) hormones function as major mediators of phenotype. Through widespread transcriptomic, physiological, and behavioral effects, GCs help vertebrates to prepare for, respond to, and recover from energetic and other challenges (e.g., Wingfield et al. 1998; Sapolsky et al. 2000; Dallman 2005; Datson et al. 2008). By altering investment in survival, reproduction, and growth, GCs also mediate life-history trade-offs (Wingfield and Sapolsky 2003). Variation in GC levels, and in the activity of the hypothalamic-pituitary-adrenal (HPA) axis that produces them, could underlie differences in the ability to inhabit challenging environments and to colonize or adapt to novel or changing environments (Liebl and Martin 2012; Angelier and Wingfield 2013). Because of their roles in matching phenotype to environment, GCs may be important targets for selection.

The basic function of the HPA axis is highly conserved across vertebrates, but circulating GC levels, like other components of HPA activity, can vary markedly (Williams 2008; Cockrem 2013). The potential for variation in GC levels to be shaped by selection has been supported by re- 
cent research in evolutionary endocrinology (e.g., Pottinger and Carrick 1999; Baugh et al. 2012; Stedman et al. 2017). Although hormone concentrations are responsive to internal and external conditions, GC levels tend to be individually repeatable traits (Taff et al. 2018a) — both under baseline conditions and following exposure to a standardized stressor ("stress-induced" GC levels). Within-population variation in GCs predicts components of fitness in a variety of contexts (e.g., Cabezas et al. 2007; Breuner et al. 2008; Bonier et al. 2009a; Romero and Wikelski 2010; Ouyang et al. 2011), although these relationships can be complex and variable (Bonier et al. 2009b; Patterson et al. 2014; Schoenle et al. 2018; Vitousek et al. 2018c). Population comparisons have also begun to elucidate how environment and life history may shape GCs and other hormones in diverging populations (Kitano et al. 2011; Schultner et al. 2013; Atwell et al. 2014; Krause et al. 2016). Whether evolution shapes GC variation in ways that are consistent across vertebrate species, however, is not well understood.

Large-scale comparisons within major vertebrate groups have begun to illuminate how GC levels vary across environments and life histories. For example, GCs increase with latitude in birds (Bókony et al. 2009; Hau et al. 2010; Jessop et al. 2013), amphibians (Eikenaar et al. 2012), and possibly reptiles (Eikenaar et al. 2012; but see Jessop et al. 2013). Thermal regimes have also been linked with GC levels in birds and reptiles (Jessop et al. 2016). To date, phylogenetically informed comparisons of endocrine traits have generally taken one of two approaches. The first is an exploratory approach (non- or weakly hypothesis driven) in which many predictor variables are included in models, with the goal of identifying factors associated with the traits of interest (e.g., Eikenaar et al. 2012; Jessop et al. 2013). The second approach entails focused tests of a specific hypothesis about how environment or life history shapes hormone variation within major vertebrate groups (e.g., birds [Goymann et al. 2004; Garamszegi et al. 2008; Bókony et al. 2009; Lendvai et al. 2013]; reptiles [Jessop et al. 2016]; mammals [Haase et al. 2016]). For example, one such analysis supported the prediction that birds actively engaging in parental care will have lower stress-induced GCs if their brood represents a greater proportion of lifetime reproductive effort (the "brood value hypothesis"; Bókony et al. 2009).

Phylogenetic comparative analyses utilizing both of these approaches have provided key insights into how selection may shape GCs; however, both approaches also suffer some drawbacks. Analyses that test a single hypothesis may not appropriately account for other confounding factors - and more importantly, they do not account for the relative contributions of different selective pressures in shaping trait variation. Exploratory analyses provide insight into the relative importance of different environmental or life-history variables, but they can be challenging to interpret, in part be- cause of the high degree of covariation among different variables of interest. For example, the relatively consistent positive relationship between latitude and GCs (Bókony et al. 2009; Hau et al. 2010; Eikenaar et al. 2012; Jessop et al. 2013) could reflect selection based on many distinct ecological pressures.

The most powerful approach to understanding GC evolution through phylogenetic comparisons involves simultaneously testing multiple distinct hypotheses about the roles of ecological and evolutionary factors within a single conceptual framework. In perhaps the best example of such an analysis to date, Hau et al. (2010) found that baseline GCs were higher in smaller-bodied passerine birds with shorter breeding seasons; stress-induced GCs were also higher in smaller passerines and positively predicted survival rates. Although this analysis was limited in its taxonomic scope, its approach holds great promise for comparing the relative strength of different predictors of GC variation across taxa.

Here we use a newly compiled database of steroid hormone levels across free-living populations (HormoneBase: https://hormonebase.org; Vitousek et al. 2018a) to test hypotheses about how selective pressures have shaped GCs across tetrapod vertebrates. At the same time, we introduce and test a broad conceptual framework about how and why GCs vary across populations and species. Because of the diversity of traits that are GC mediated, the specific pathways by which HPA activity affects fitness are undoubtedly highly variable. Yet commonalities may exist in how environments or life histories shape HPA activity. We propose that macroevolutionary patterning of GC levels across vertebrates can be broadly characterized as reflecting either "supportive" or "protective" processes. The supportive functions of GCs entail helping organisms prepare for, respond to, and recover from challenges (e.g., through permissive, stimulatory, preparative, and suppressive GC actions; Sapolsky et al. 2000), including through supporting energetically demanding activities (see below). If selection favors a supportive role for GCs, GC levels should be higher in environments and during life-history stages where challenges are more common. Alternatively, selection could favor protection from elevated GC concentrations because high GCs can impair reproductive processes and cause pathological tissue damage (e.g., Wingfield and Sapolsky 2003; Romero et al. 2009). In this case, GC levels may be lower where challenges are likely to be frequent or prolonged and during life-history stages where the costs of high GCs may be particularly severe. To our knowledge, a similar framework has not previously been applied to macroevolutionary patterning in GCs; however, the framework developed here has some consistencies with hypotheses proposed to explain seasonal changes in GCs (e.g., the preparative and energy mobilization hypotheses vs. the behavioral hypothesis; Romero 2002; Romero et al. 2017) and with hypotheses about GC-fitness relationships 
within populations (Wingfield et al. 1998; Bonier et al. 2009a; Schoenle et al. 2018).

In this analysis, we first test the relative support for seven hypotheses about GC evolution (table 1) and then evaluate whether these results provide support for general patterns in GC variation across populations and species (supportive and/or protective). For four of our hypotheses, we predicted a relationship consistent with GCs playing a supportive role in challenging conditions. Note that for many of these hypotheses a significant relationship opposite to that predicted here would instead support the role of protective processes in shaping GCs. Because smaller organisms generally have fewer energetic reserves and must thus respond rapidly and effectively to energetic challenges, we predicted that (1) body size would be negatively associated with GC levels, consistent with several prior analyses (baseline [Bókony et al. 2009; Hau et al. 2010; Haase et al. 2016]; stress-induced [Hau et al. 2010; Haase et al. 2016; Jessop et al. 2016; but see Bókony et al. 2009]). Similarly, we predicted that when controlling for body size, (2) species with a higher metabolic rate (and thus greater energy needs) would have higher GC levels. Although this relationship is widely predicted (e.g., McEwen and Wingfield 2003; Romero et al. 2009; Jimeno et al. 2017), it has been tested only in two recent phylogenetically informed comparisons, which found conflicting patterns (Haase et al. 2016; Francis et al. 2018). Because of the role of GCs in regulating energy storage and use (Sapolsky et al. 2000; Landys et al. 2006; Hau et al. 2010), we predicted that (3) more energetically demanding or challenging environments would be associated with higher GCs. For example, because cold environments tend to impose greater energetic costs on endotherms, which often expend substantial energy to maintain homeostasis in cold environments (e.g., Scholander et al. 1950; Weathers 1979; Anderson and Jetz 2005), we predicted a negative relationship between ambient temperature and GCs in endotherms. By contrast, because energetic expenditure generally increases with temperature in ectotherms (e.g., Andrews and Pough 1985; Schmidt-Nielsen 1997), we predicted a positive relationship between temperature and GCs in ectotherms. We also predicted that drier environments - which tend to have lower levels of vegetation (and potentially lower resource availability) — would be associated with higher GC levels. Finally, because environmental uncertainty could pose particular challenges to homeostasis (Jetz and Rubenstein 2011; Wingfield 2013b), we predicted that (4) environments with greater variation in temperature and precipitation would be associated with higher baseline and/or stress-induced GCs.

Although GCs are important mediators of the response to challenges, substantially or chronically elevated GCs can also impose major phenotypic and fitness costs. Several of our predictions were consistent with protective processes shaping GC evolution - particularly for stress-induced GCs. Because high GC levels can impair reproduction (Wingfield and Sapolsky 2003), we predicted that (5) during the breeding season, species with fewer lifetime reproductive opportunities would have lower GC levels (O'Reilly and Wingfield 2001; Bókony et al. 2009). High GC levels, especially when chronically elevated, can also accelerate aging and reduce life span, potentially through increasing oxidative stress and reducing telomere length (Haussmann and Marchetto 2010; Costantini 2011; Angelier et al. 2018; Schoenle et al. 2018). Thus, we predicted that (6) longer-lived species would have lower GC levels. Finally, we hypothesized that organisms that experience frequent or pervasive social stressors would benefit from lower stress-induced GCs. The GC stress response is a nonspecific response triggered by many types of challenges. Although the GC response is particularly well suited for coping with immediate threats to survival, it is also triggered by challenges that pose little threat to immediate survival (e.g., Goymann and Wingfield 2004; Creel et al. 2013; Cavigelli and Caruso 2015; Schoenle et al. 2018). Because of the potential for socially induced GC responses to incur costs, we

Table 1: Potential predictors of glucocorticoids (GCs): hypotheses, predicted relationships, and candidate models

\begin{tabular}{|c|c|c|c|}
\hline Hypothesis & Predicted relationship with GCs & Predicted role of GCs & Single-hypothesis model ${ }^{a}$ \\
\hline Body size & Negative & Supportive & Body mass \\
\hline Metabolic rate & Positive & Supportive & Metabolic rate + body mass \\
\hline Environment & $\begin{array}{l}\text { Temperature: negative endotherms, } \\
\text { positive ectotherms; precipitation: } \\
\text { negative }\end{array}$ & Supportive & $\begin{array}{l}\text { Mean seasonal temperature } \times \\
\text { thermoregulatory status } \\
\text { (endotherm/ectotherm) }+ \text { mean } \\
\text { seasonal precipitation }\end{array}$ \\
\hline Environmental variation & Positive & Supportive & $\begin{array}{l}\text { Environmental variation (principal } \\
\text { components } 1 \text { and } 2 \text { ) }\end{array}$ \\
\hline Reproductive attempts & Positive (length of breeding season) & Protective & $\begin{array}{l}\text { Maximum lifetime reproductive attempts } \times \\
\text { life-history stage (breeding/nonbreeding) }\end{array}$ \\
\hline Longevity & Negative & Protective & Maximum longevity \\
\hline Sociality & Negative & Protective & Sociality (group living, paired, solitary) \\
\hline
\end{tabular}

\footnotetext{
a All candidate models included additional random and fixed effects as specified in the main text.
} 
predicted that (7) sociality (here considered as group living) would be negatively associated with GCs across vertebrates.

Variation in baseline and stress-induced GC levels were considered separately — using parallel analyses - because of the mounting evidence that these traits may be differently shaped by selection. Although baseline and stress-induced GCs are often phenotypically correlated, they do not appear to be genetically correlated (Satterlee and Johnson 1988; Pottinger and Carrick 1999; Baugh et al. 2012; Jenkins et al. 2014; Stedman et al. 2017). The transcriptomic, physiological, and phenotypic effects of baseline and stress-induced GCs can also differ markedly. Baseline GCs predominantly bind to high-affinity mineralocorticoid receptors, mediating feeding behavior and regulating metabolism (Landys et al. 2006). Mineralocorticoid receptors, which are present in relatively low concentrations, are typically nearly saturated at baseline levels (Sapolsky et al. 2000; Romero 2004). During an acute stress response, GC levels rise dramatically; excess GCs bind at GC receptors, inducing phenotypic changes important for coping with immediate stressors (e.g., energy mobilization, increases in blood pressure and cardiac output, changes in immune responses, and reproductive suppression; Sapolsky et al. 2000). Consistent with their differential phenotypic effects, baseline and stress-induced GC levels often differ in their relationship with fitness (Blas et al. 2007; Angelier et al. 2009; Ouyang et al. 2013; Patterson et al. 2014; Vitousek et al. 2018c). Despite these differences, GC levels in both contexts could be important for coping with risky or energetically demanding environments.

\section{Methods \\ Hormone Data}

Data on circulating GC levels were obtained from HormoneBase (Vitousek et al. 2018a), a publicly available resource of plasma steroid hormone levels across vertebrate populations (currently including 2,600 measures of GC levels from tetrapods). All measures in HormoneBase come from adults in free-living populations in which the sexes were not pooled. Our analysis used data on mean GC levels for each sex; where provided, separate means were included from individuals in different life-history stages. For this analysis, HormoneBase data were subject to a strict filtering protocol. To attempt to ensure that we were comparing true baseline measures (rather than measures in which GC levels had begun to rise as a result of capture and handling), we excluded all baseline samples collected more than 3 min after capture in birds and mammals, more than $5 \mathrm{~min}$ postcapture in other vertebrates, or where sampling latency was not reported.

The HormoneBase data set also includes measures of peak plasma GC levels in response to restraint stressors. The time between stressor exposure and peak GC levels differs by species; in most vertebrates, peak levels are achieved
15-60 min after the onset of a stressor, but particularly in reptiles, GC levels can continue to increase for hours. HormoneBase includes all measures characterized by the authors as representing acute stress-induced GCs; if multiple samples were collected from the same individuals or group of individuals during a stress series, only peak concentrations were included. For this analysis, we excluded stress-induced GC measures taken more than $60 \mathrm{~min}$ postcapture unless it was verified that the selected sampling window represented peak concentrations. Because baseline and stress-induced GCs can covary (Haase et al. 2016; but see Hau et al. 2010), analyses of stress-induced GCs included baseline levels as a covariate; thus, records were excluded from analysis if baseline measures were not also available. Analyses of stressinduced GCs used a slightly less strict threshold to exclude records based on sampling latency (as sample sizes were already small in some taxa and baseline GCs were included only as a covariate): baseline measures were excluded when collected more than $5 \mathrm{~min}$ after capture across all vertebrate groups. Following these filtering protocols, very few fish species were retained in the data set; thus, fish were excluded from analyses.

Analyses were conducted on a filtered data set that included 1,529 measures of mean GC levels. Of these measurements, 1,121 represented baseline GCs, measured from 187 species in 278 locations, and 407 means of stress-induced GCs were included, measured from 74 species in 146 locations. The filtered data set included the following numbers of population/group means: 136 from amphibians (25 species), 69 from mammals (seven species), 301 from reptiles (44 species), and 1,022 from birds (116 species). The filtered data sets used for this analysis are available in the Dryad Digital Repository: https://dx.doi.org/10.5061/dryad.th03671 (Vitousek et al. 2019).

\section{Phylogenetic Tree}

A species-level phylogenetic tree of the species included in HormoneBase was constructed as described by Johnson et al. (2018). Briefly, beginning with a time-dated backbone phylogeny from the TimeTree of Life (Kumar et al. 2017), we manually modified the date of the amphibian stem node by shifting it to correspond with Roelants et al. (2007), while ensuring that the tree remained ultrametric. Taxonomy was matched between HormoneBase and major lineage-specific trees for amphibians (Pyron and Wiens 2011; Eastman et al. 2013), mammals (Bininda-Emonds et al. 2007), squamates (Pyron et al. 2013), turtles (Jaffe et al. 2011), and birds (Jetz et al. 2012), ensuring that each row in the database matched a single tip in its respective lineage-specific tree. The mammal tree was resolved, and the subtrees were pruned and bound (see Johnson et al. 2018). Following the data-filtering protocols described above, a final tree for this analysis was created 
from the HormoneBase tree (provided in Johnson et al. 2018) by dropping tips from that tree.

Environmental data. Data on mean monthly temperature and precipitation for each study location were obtained from the Climatic Research Unit (CRU) Time-Series Data (Harris et al. 2014), which provides data on monthly variation in global climate in $0.5^{\circ}$ grids. From these data, we calculated the 51-year average (which represents the period of time over which the majority of HormoneBase data were collected: 1965-2015) of seasonal mean temperature and precipitation and of inter- and intraseasonal variation (standard deviation) in temperature and precipitation for all study locations. Seasons (3-month intervals) were grouped as follows: March-May, June-August, September-November, December-February.

Because our data set contained migrants and residents, as well as species with very different geographical ranges, we restricted environmental analyses to the season in which samples were collected. HormoneBase includes information on the months in which data were collected for each entry; when months were not specified in the original article, we used information on the season in which data were collected. To enable comparison on a similar timescale, each study was assigned a single season (3-month intervals as specified above). Samples collected in multiple seasons were assigned to the first season (if sampled in two seasons) or the middle season (if sampled in three seasons). Studies that pooled measures across all four seasons or across multiple nonconsecutive seasons were discarded from this analysis, as were studies that did not specify the month or season of sample collection. Because CRU data are available only for terrestrial locations, we were not able to obtain environmental data for populations sampled in aquatic environments; thus, exclusively aquatic tetrapods are not included in this analysis. However, many of the measures included in this analysis come from tetrapods that utilize both terrestrial and aquatic environments.

\section{Life-History and Metabolic Data}

To test hypotheses about the evolution of GC levels, we compiled life-history data on all species contained in the HormoneBase database. Whenever possible, we included data that were specific to the population in which samples were collected; when those data were not available, we included information on species means. Life-history data were obtained from the primary literature, including the articles in which hormone data were reported, other studies from the same population, and public databases (e.g., AnAge [de Magalhaes 2004]; AmphiBIO [Oliveira et al. 2017]; the Birds of North America [Rodewald 2015]). Traits included male and female body mass, maximum longevity, sex-specific time to maturity, and the average number of reproductive events per year (litters, clutches, etc.). Species were also classified by their degree of sociality (group living, pair living, solitary) during the breeding season and the nonbreeding season. Each measure of hormone data was also associated with information about whether samples were collected during the breeding season or nonbreeding season; when samples were collected across both seasons or from a combination of breeding and nonbreeding individuals, they were classified as breeding. To test hypotheses about reproductive value, we estimated the maximum number of lifetime reproductive attempts possible for each sex in each population using the following formula: maximum lifetime reproductive attempts $=$ (maximum longevity - time to maturity $) \times$ average number of reproductive attempts per year. This metric is similar to that utilized by Bókony et al. (2009) but focuses on total potential reproductive attempts rather than the proportion of reproductive effort represented by each attempt. It was designed to utilize life-history data that is relatively widely available across taxa and to be applicable to species with a diversity of reproductive strategies (e.g., across taxa with substantial variation in clutch size and parental care).

The protocol for compiling and validating transformations of metabolic data is described in full by Johnson et al. (2018). In brief, data on whole-animal standard metabolic rates for ectotherms or basal metabolic rates for endotherms were compiled from the primary literature and existing reviews (e.g., White et al. 2006; Uyeda et al. 2017) and converted into watts (Gessaman and Nagy 1988). Temperatureindependent standard metabolic rates were determined for ectotherms by extracting residuals from linear regression models between temperature and metabolic rate (Downs et al. 2008; Johnson et al. 2018). Basal metabolic rates were not corrected for body temperature, as temperature varies relatively little across endotherms and has a small, although significant, effect on basal metabolic rate (McNab 1997; White and Seymour 2003; Clarke et al. 2010).

We were not able to obtain life-history or metabolic data on all species included in this analysis (mean: $83 \%$ completeness across the traits used here). As neither MCMCglmm nor model comparison analyses allow missing data, we used the package Rphylopars (Goolsby et al. 2017) to impute missing data across all 474 species in the HormoneBase database. Rphylopars uses a linear-time algorithm to reconstruct ancestral states, impute missing data, and compute species means according to an estimated evolutionary model. This analysis used the phylogenetic tree specified above and the default parameters in Rphylopars, including a Brownian motion model of evolution. We performed imputations of multiple variables simultaneously for each vertebrate group, using groups of related variables such that covariances among the traits contributed to the imputed results. Imputed data were manually checked to ensure correspondence with biological realism as follows. When imputed values were negative (approximately $1 \%$ of the life-history values in this analysis), we re- 
placed the imputed data with values from a congener (if available). If data from multiple congeners were available, we used the lowest value reported for a congener. If data from a congener were not available, we replaced the negative imputed values with the minimum nonimputed value for the trait, following the standard approach for hormone levels whose measured values are below the detection limit of an assay. In addition, for two of the species in this analysis, the imputed average life expectancy was greater than the imputed maximum longevity value. In these two cases, we replaced the imputed maximum longevity value with the imputed average life expectancy for that species.

\section{Statistical Analysis}

The package MCMCglmm (Hadfield 2010) was used in the $\mathrm{R}$ environment to compare candidate models of baseline and stress-induced GC levels (code is available from the authors upon request). Prior to analysis, hormone data and other continuous variables were natural log transformed; before transformation, a constant was added to seasonal mean temperature $(+30)$ to ensure that all values were greater than zero. Candidate models used a Gaussian distribution and specified relatively uninformative inverse gamma priors $(v=1, \nu=0.002)$. Models were run for $1,000,000$ iterations with a burn-in of 50,000 and a thinning of 200. Models were checked by visually inspecting density and trace plots for independence and consistency of the posterior distributions and by checking autocorrelation values (Hadfield 2010), which were all $<0.05$. To confirm the stability of results, each model was fitted three times. Models were also rerun with highly informative priors $(\nu=1)$ to confirm that prior specification did not impact results (Wilson et al. 2009).

Generalized linear mixed models included species (the matrix of phylogenetic relatedness) and population identity as random effects. Because measured hormone levels can differ among labs (Fanson et al. 2017), we also included hormone lab identity (as described in Vitousek et al. 2018b) as a random effect. In addition, all models included the fixed effects of sex and GC type (corticosterone or cortisol). Models of stress-induced GC levels also included baseline GC levels as a fixed effect. Single-hypothesis models (table 1) were competed against an omnibus model that contained all of these fixed effects and interactions, an intercept-only model, and a model that included only sex, GC type, and, for models of stress-induced GCs, baseline GCs. Relative model fit was assessed using deviance information criterion scores. Figures in the text show model-predicted relationships; raw data are shown in supplemental materials (figs. S1-S6, available online).

Because measures of environmental variation on different timescales (inter- and intraseasonal variation in temperature and precipitation) were correlated, we ran a principal component (PC) analysis on centered and scaled environmental variation data. Two PCs explained $89.3 \%$ of the variance in the data set. $\mathrm{PC} 1$ (eigenvalue $=2.4$; variance explained $=61.0 \%$ ) had strong positive loading $(>0.50)$ on intra- and interseasonal SD in precipitation and strong negative loading on inter- and intraseasonal SD in temperature (variable precipitation, consistent temperature). PC2 (eigenvalue $=1.1$; variance explained $=28.4 \%$ ) had strong positive loading on all measures of variation (intra- and interseasonal temperature and precipitation). The full loading matrix is provided in table S1 (available online).

\section{Results}

The best-fit model of baseline GC levels was the omnibus model (table 2). Within this model (table 3), baseline GCs were negatively associated with body mass. As predicted, the relationship between seasonal mean temperature and baseline GCs differed in endotherms and ectotherms. In endotherms, temperature was negatively associated with baseline GCs, whereas ectotherms showed a positive relationship (fig. 1). The omnibus model also supported the presence of differences in the relationship between reproductive value (maximum lifetime reproductive attempts) and baseline GCs during the breeding and nonbreeding seasons. During the breeding season, baseline GCs were negatively associated with the maximum number of lifetime reproductive attempts; this pattern was not seen in the nonbreeding season (fig. 2A). Baseline GC levels did not differ significantly between the sexes, and GC type (corticosterone/cortisol) was not associated with circulating baseline levels (table 3).

Table 2: Comparison of candidate models of baseline glucocorticoids (GCs)

\begin{tabular}{lccc}
\hline Model & DIC & $\Delta$ DIC & Weight \\
\hline $\begin{array}{l}\text { Omnibus } \\
\text { Temperature } \times \text { thermoregulatory }+\end{array}$ & $2,153.2$ & 0 & .95 \\
$\quad$ precipitation & $2,159.1$ & 5.9 & .05 \\
$\quad$ Mass & $2,181.6$ & 28.4 & .00 \\
Mass + metabolic rate & $2,181.7$ & 28.5 & .00 \\
$\quad \begin{array}{l}\text { Reproductive attempts } \times \\
\quad \text { breeding status }\end{array}$ & $2,187.9$ & 34.7 & .00 \\
Longevity & $2,189.6$ & 36.4 & .00 \\
Sex + GC type & $2,189.6$ & 36.4 & .00 \\
$\quad$ Environmental variation & & & \\
$\quad$ PC1 + PC2) & $2,191.3$ & 38.1 & .00 \\
Intercept only & $2,192.2$ & 39.0 & .00 \\
Social & $2,193.3$ & 40.1 & .00 \\
\hline
\end{tabular}

Note: All models except for the intercept-only model include sex and GC type as fixed effects. DIC = deviance information criterion; $\mathrm{PC}=$ principal component. 
Table 3: Best-fit omnibus model of baseline glucocorticoids (GCs)

\begin{tabular}{|c|c|c|c|c|c|}
\hline Predictor & Posterior mean & Lower 95\% CI & Upper 95\% CI & Effective sample size & $p \mathrm{MCMC}$ \\
\hline (Intercept) & -1.753 & -4.815 & 1.216 & 4,496 & .250 \\
\hline Body mass & -.188 & -.313 & -.066 & 4,750 & .003 \\
\hline Metabolic rate & .022 & -.111 & .144 & 4,750 & .741 \\
\hline Reproductive attempts & -.105 & -.379 & .163 & 4,750 & .435 \\
\hline Breeding status (nonbreeding) & -.643 & -1.149 & -.181 & 5,303 & .012 \\
\hline Reproductive attempts $\times$ breeding status & .186 & .031 & .349 & 5,189 & .029 \\
\hline Longevity & .185 & -.210 & .576 & 4,750 & .349 \\
\hline Social (pair) & .069 & -.169 & .321 & 4,750 & .578 \\
\hline Social (solitary) & .011 & -.320 & .318 & 5,098 & .937 \\
\hline Temperature & 1.224 & .574 & 1.879 & 4,750 & .001 \\
\hline Thermoregulatory (endothermy) & 8.388 & 4.989 & 11.991 & 4,750 & $<.0002$ \\
\hline Temperature $\times$ thermoregulatory & -1.698 & -2.399 & -.951 & 4,750 & $<.0002$ \\
\hline Precipitation & -.116 & -.195 & -.046 & 4,750 & .004 \\
\hline Environmental variation (PC1) & .051 & -.025 & .134 & 4,750 & .203 \\
\hline Environmental variation (PC2) & .065 & -.048 & .178 & 4,750 & .263 \\
\hline Sex (male) & -.037 & -.119 & .046 & 3,657 & .407 \\
\hline GC type (cortisol) & -.085 & -1.933 & 1.847 & 4,515 & .924 \\
\hline
\end{tabular}

Note: Marginal $R^{2}=0.803$, conditional $R^{2}=0.987$. Fixed effects are shown in boldface if the $95 \%$ confidence interval (CI) of the mean does not cross zero. $\mathrm{MCMC}=$ Markov chain Monte Carlo; $\mathrm{PC}=$ principal component.

The best-fit model of stress-induced GCs included the interaction between reproductive value and breeding season, in addition to the fixed effects included in all candidate models in this set (tables 4, 5; marginal $R^{2}=0.307$, conditional $R^{2}=0.979$ ). During the breeding season, species that had more lifetime reproductive attempts had lower stressinduced GCs. The opposite pattern was seen during the nonbreeding season (fig. 2B). The relative weights of all other candidate models were substantially lower than the weight of the top model (table 4). Stress-induced GCs were significantly higher in males than in females (table 5). GC type did not predict stress-induced GC levels, but baseline GCs positively predicted stress-induced GCs across taxa (table 5).

Best-fit models for both baseline and stress-induced GCs showed evidence of a strong phylogenetic signature (Pagel's $\lambda$ : baseline $=0.89$, stress-induced $=0.88$ ). The random effects of species and population were significant in both models (posterior means and confidence intervals; baseline: species $=2.74[1.36-4.15]$, population $=0.25[0.14-0.38]$; stress-induced: species $=0.69[0.30-1.10]$, population $=$ $0.02[0.00-0.05])$. The random effect of lab identity was also significant in both models, although the effect was substantially weaker for stress-induced GCs (baseline: 0.35 [0.25$0.38]$; stress-induced: 0.05 [0.01-0.11]).

\section{Discussion}

\section{General Patterns in GC Variation: Supportive or Protective?}

The presence of patterns in GC levels across broad taxonomic scales suggests a surprising degree of consistency in how at least some selective pressures shape GCs. At the same time, the nature of these patterns suggests that selection operates on baseline and stress-induced GC levels in distinct ways in challenging environments. All of the factors that predicted baseline GCs across tetrapod vertebrates were consistent with selection favoring higher baseline levels in challenging contexts (supportive effects; fig. 3), which may occur because of the roles of GCs in regulating metabolism and supporting energetically demanding activities (Landys et al. 2006; Hau et al. 2010; Crespi et al. 2013). By contrast,

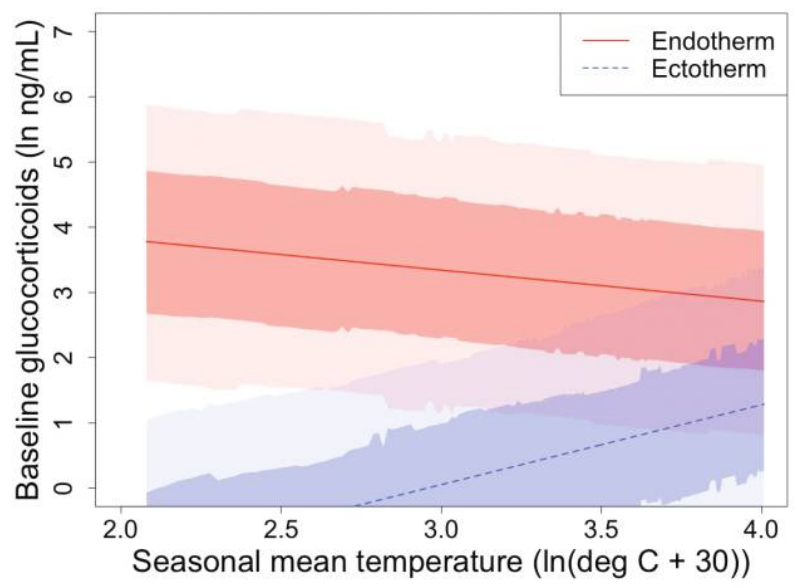

Figure 1: Baseline glucocorticoid levels in endotherms and ectotherms as a function of mean temperature during the season of measurement. Shaded areas represent the Bayesian credible interval around the posterior distribution of the mean (light: $90 \%$, dark: 60\%). 

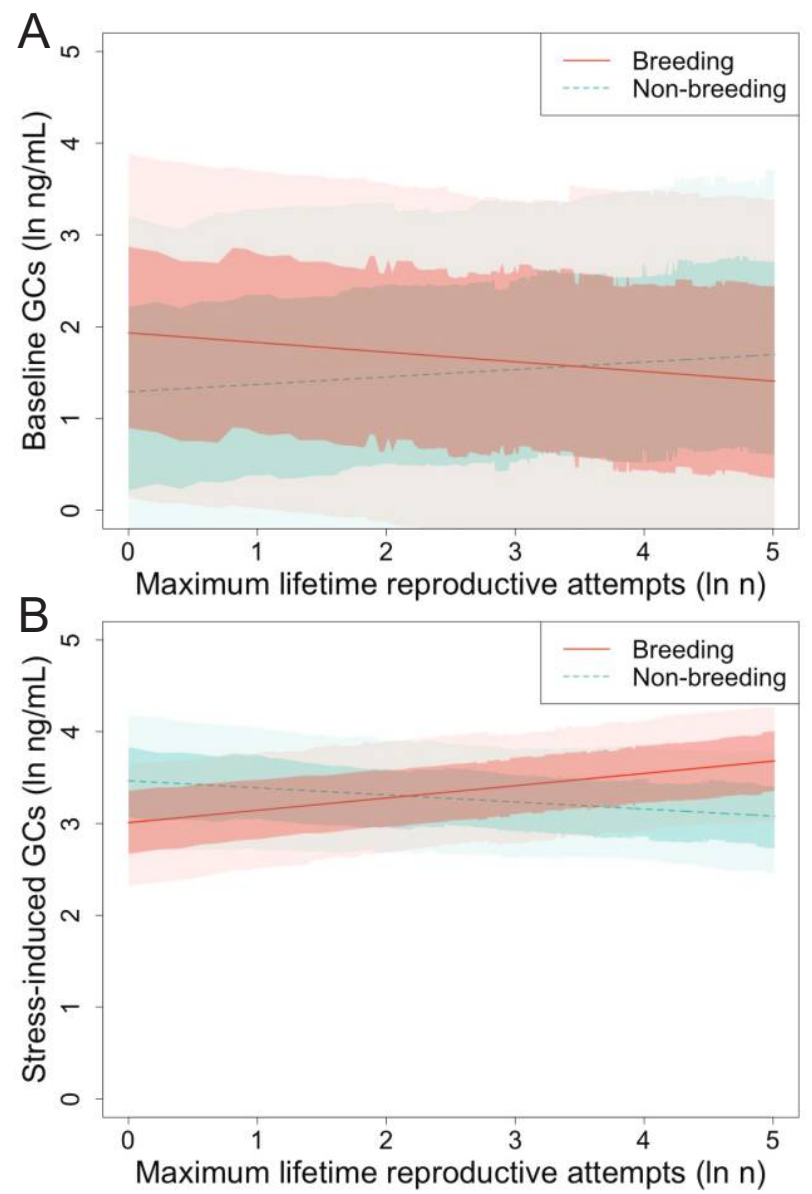

Figure 2: Baseline (A) and stress-induced (B) glucocorticoid (GC) levels in breeding and nonbreeding tetrapods as a function of maximum lifetime reproductive attempts. Shaded areas represent the Bayesian credible interval around the posterior distribution of the mean (light: $90 \%$, dark: 60\%).

at least at the broad taxonomic scales analyzed here, patterns in stress-induced GCs were more consistent with selection favoring protection from the deleterious effects of high GCs (protective effects), particularly during GC-vulnerable life-history stages (O'Reilly and Wingfield 2001; Wingfield and Sapolsky 2003).

If mounting a strong GC response is integral to effectively coping with challenges, why do we not see that stress-induced GCs are generally higher in more challenging environments? One possibility is that the contexts under which mounting a strong GC response outweighs its costs are highly variable across populations and species. Although slight elevations in baseline GCs may carry relatively minor costs, the high levels of GCs present during an acute stress response- and particularly their increased binding at GC receptors - induce massive changes in gene expression, physiology, and behavior. These changes could have rapid fitness effects and induce patho- logical tissue damage over longer timescales (Sapolsky et al. 2000; Lupien et al. 2009; Romero et al. 2009; Goerlich et al. 2012). The conditions under which such a response is adaptive may depend heavily on the specific nature of the stressor and whether its effects can be escaped or mitigated through GC-mediated phenotypic changes (Schoenle et al. 2018). For example, mounting a moderate GC response to localized food limitation is likely to be adaptive when GCs promote increased foraging behavior, leading to the discovery of novel food sources (Landys et al. 2006). By contrast, when food limitation is widespread and increased foraging yields little benefit, the costs of mounting a stronger or longer GC response are more likely to outweigh its benefits (Romero and Wikelski 2010; Schoenle et al. 2018). Our results suggest that while the costs of high stress-induced GC levels during particularly high-value reproductive attempts are fairly universal across tetrapods, the contexts under which high stress-induced GCs are favored may be more variable. It is also possible that in challenging environments selection operates more strongly or consistently on aspects of the HPA axis other than those influencing maximum circulating hormone levels (e.g., receptor density or distribution, binding proteins or cofactors, or the ability to rein in the GC response through negative feedback). The higher baseline GC levels in tetrapods inhabiting more challenging environments could also reflect altered acute stress responses. Within species, baseline GCs can prime the acute stress response (Sapolsky et al. 2000), promoting a more rapid and effective response to subsequent challenges (Vera et al. 2017; Del Giudice et al. 2018). In this analysis, baseline GC levels positively predicted stress-induced levels. Thus, the overall patterns seen here suggest that across tetrapods, selection could be favoring elevated baseline GC levels in riskier or more challenging environments because of the role of GCs in priming more effective or efficient phenotypic responses to acute challenges.

Table 4: Comparison of candidate models of stress-induced glucocorticoids (GCs)

\begin{tabular}{lccc}
\hline Model & DIC & $\Delta$ DIC & Weight \\
\hline Reproductive attempts $\times$ breeding status & 318.1 & 0 & .99 \\
Sociality & 328.6 & 10.5 & .01 \\
Omnibus & 331.2 & 13.1 & .00 \\
Environmental variation $(\mathrm{PC} 1+\mathrm{PC} 2)$ & 335.8 & 17.7 & .00 \\
Longevity & 336.6 & 18.5 & .00 \\
Sex + GC type + baseline GC level & 336.7 & 18.6 & .00 \\
Mass & 336.9 & 18.8 & .00 \\
Metabolic rate + mass & 337.8 & 19.7 & .00 \\
Temperature $\times$ thermoregulatory + & & & \\
$\quad$ precipitation & 479.1 & 161.0 & .00 \\
Intercept only & 482.7 & 164.6 & .00 \\
\hline
\end{tabular}

Note: All models except for the intercept-only model include sex, GC type, and baseline GC level as fixed effects. DIC = deviance information criterion; $\mathrm{PC}=$ principal component. 
Table 5: Best-fit model of stress-induced glucocorticoids (GCs)

\begin{tabular}{lccccc}
\hline Predictor & Posterior mean & Lower 95\% CI & Upper 95\% CI & Effective sample size & $p$ MCMC \\
\hline (Intercept) & 2.140 & 1.314 & 2.976 & 4,750 & $<.0002$ \\
Reproductive attempts & $\mathbf{. 1 3 4}$ & $\mathbf{. 0 0 6}$ & $\mathbf{. 2 6 0}$ & $\mathbf{4 , 7 5 0}$ & $\mathbf{. 0 4 0}$ \\
Breeding status (nonbreeding) & $\mathbf{. 4 5 6}$ & $\mathbf{. 0 2 8}$ & $\mathbf{. 9 0 1}$ & $\mathbf{4 , 4 6 5}$ & $\mathbf{. 0 4 3}$ \\
Reproductive attempts $\times$ breeding status & -.207 & -.352 & -.072 & $\mathbf{4 , 3 9 2}$ & $\mathbf{. 0 0 5}$ \\
Sex (male) & $\mathbf{. 1 5 5}$ & $\mathbf{. 0 7 9}$ & $\mathbf{. 2 3 6}$ & $\mathbf{4 , 7 5 0}$ & $<.0002$ \\
GC type (cortisol) & .719 & -.306 & 1.659 & 4,750 & .147 \\
Baseline GC level & $\mathbf{. 4 1 8}$ & $\mathbf{. 3 5 8}$ & $\mathbf{. 4 7 2}$ & $\mathbf{4 , 7 5 0}$ & $<.0002$ \\
\hline
\end{tabular}

Note: Marginal $R^{2}=0.307$; conditional $R^{2}=0.979$. Fixed effects are shown in boldface where the $95 \%$ confidence interval (CI) of the mean does not cross zero. MCMC = Markov chain Monte Carlo.

\section{Comparing Specific Hypotheses of GC Variation}

Body mass was strongly negatively associated with baseline GCs across tetrapods, as previously reported in analyses within vertebrate groups (birds [Bókony et al. 2009; Hau et al. 2010]; mammals [Haase et al. 2016]). Unlike some previous analyses (reptiles [Jessop et al. 2013]; mammals [Haase et al. 2016]; birds [Hau et al. 2010; but see Bókony et al. 2009]), body mass was not a good predictor of stress-induced GCs. A negative body mass-baseline GC relationship is consistent with the hypothesis that in smaller organisms, which have lower energetic reserves than larger organisms, it is relatively more important to be able to quickly mobilize energy and to prepare for and respond effectively to challenges. We found no support for the related hypothesis that baseline GC levels would be positively associated with metabolic rate. This relationship has been widely predicted (e.g., McEwen and Wingfield 2003; Romero et al. 2009) and could result from higher metabolic rates reducing energy reserves (Hau et al. 2010; Jimeno et al. 2017) or because increased metabolic clearance rates require more hormones to produce the same effect. But to our knowledge only two prior studies have tested these relationships across species, with differing results (Haase et al. 2016; Francis et al. 2018). We found that metabolic rate

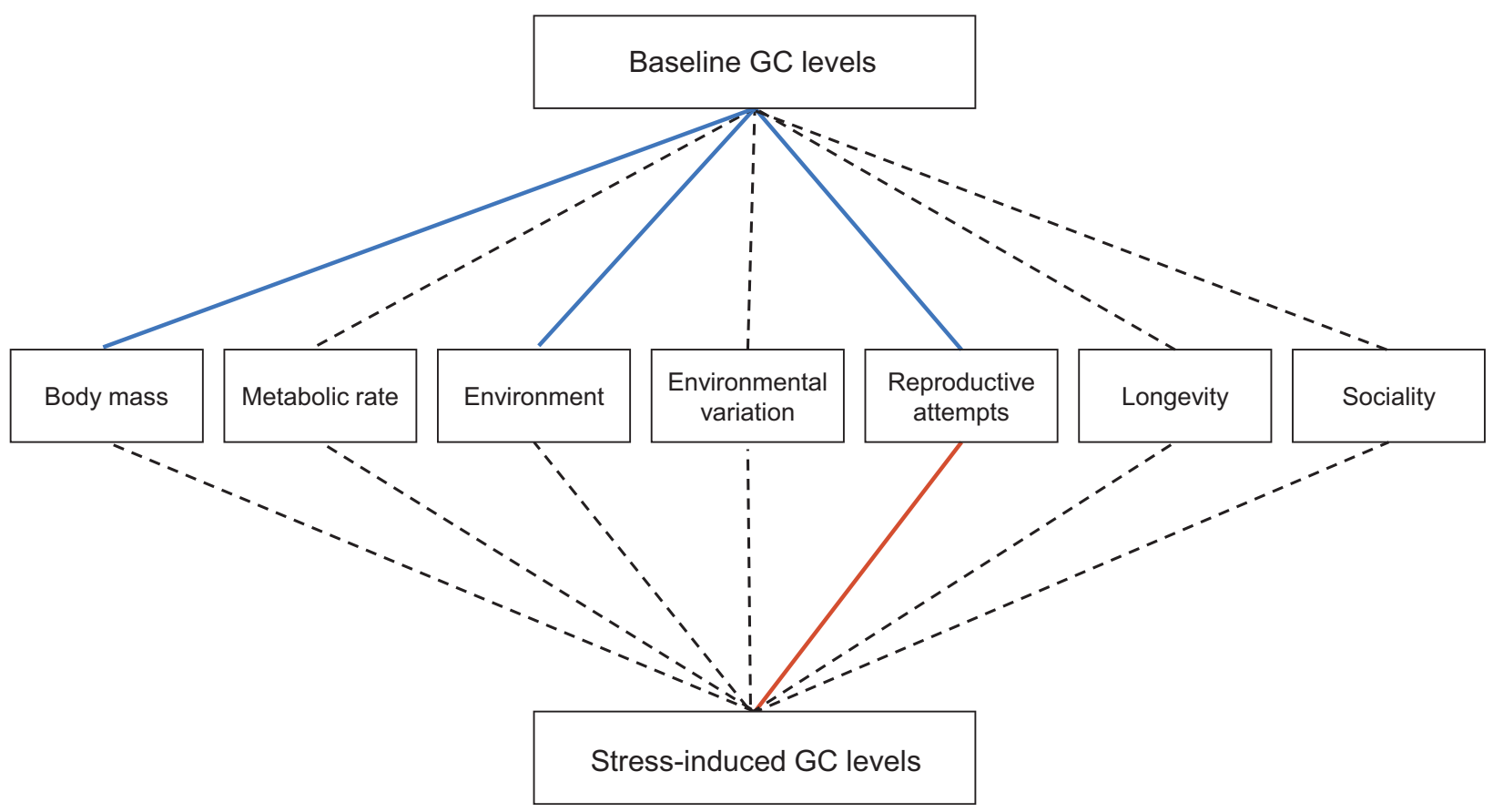

Figure 3: Predictors of glucocorticoid (GC) variation across tetrapod vertebrates and their implications for the supportive and protective hypotheses. The middle row of boxes represents environmental and life-history variables predicted to influence GC levels (see table 1). Dashed lines between these variables and GC levels indicate relationships not strongly supported in our analyses; solid lines represent relationships that received substantial support. Among supported predictors, those where the direction of the relationship is consistent with a supportive role of GCs are shown in blue, and those with a protective role of GCs are shown in red. 
was not a significant predictor within the omnibus model (defined here as an effect for which the 95\% confidence interval of the posterior mean does not cross zero). Similarly, for both baseline and stress-induced GCs, the candidate models that included both metabolic rate and body mass had slightly poorer fits to the data than the models that contained body mass alone. The apparent absence of metabolic scaling of GC levels could be an artifact of low statistical power and/ or result from noise introduced by the phylogenetic imputation of metabolic data; of all the life-history and phenotypic traits included in this analysis, metabolic rate was available for the fewest populations and species (amphibians are particularly poorly represented; Johnson et al. 2018). Alternatively, because GCs play important roles in mediating energy mobilization (Sapolsky et al. 2000) and promoting activity (Landys et al. 2006; Welcker et al. 2015), it is also possible that GC variation is more closely associated with measures of energy use that incorporate activity (e.g., daily energetic expenditure, maximal metabolic rate) than with the maintenance costs assessed here (basal metabolic rate/standard metabolic rate).

Baseline GC levels were also higher in more energetically costly thermal environments. As predicted, the relationship between baseline GCs and mean seasonal temperature differed according to thermoregulatory strategy. Endotherms, which generally face greater energetic demands in cold environments due to the cost of thermoregulation (Scholander et al. 1950; Weathers 1979; Anderson and Jetz 2005), had higher baseline GCs when inhabiting colder environments. In ectotherms, where metabolic rates generally scale positively with ambient temperature (Andrews and Pough 1985; Schmidt-Nielsen 1997), baseline GCs were somewhat higher in warmer environments. By contrast, mean seasonal temperatures did not predict stress-induced GCs. These findings are consistent with selection favoring higher baseline GCs-but not stress-induced GCs - when energetic need is greater.

The general pattern of higher baseline GC levels in more energetically demanding thermal environments is consistent with that seen by Hau et al. (2010), although that analysis characterized environments categorically (e.g., mesic, tropical, cold, arid). The GC-temperature patterns seen here differ somewhat from those in a recent comparative analysis focusing on thermal dependence of GC responses in birds and reptiles (Jessop et al. 2016), which tested whether the annual thermal characteristics of the environments predicted GC levels (regardless of whether the species in question were present or active year-round). In that analysis, baseline GCs were higher in reptiles inhabiting environments with cooler mean annual temperatures and higher in birds inhabiting environments with greater maximum annual temperatures; stress-induced GCs were higher in environments with lower minimum annual temperatures in birds but were unrelated to annual environmental temperature in reptiles (Jessop et al. 2016). The discrepancies between the findings of this analysis and that of Jessop et al. (2016) could result from differences in the environmental parameters tested: our analysis used environmental data only from the season in which populations were sampled in a given location, rather than characterizing measures of seasonality or annual environments at a given location. We made the decision to focus on environmental data from the season of measurement because many populations in this data set are migratory and because GC levels can change within populations or individuals across seasons (Romero 2002). Nevertheless, environmental seasonality may play an important role in driving patterns of resource availability and relative risk, in addition to thermal evolution, in ways that could shape GC levels at macroevolutionary scales.

Precipitation levels strongly and negatively predicted baseline GCs but not stress-induced GCs. This pattern is consistent with baseline GCs being elevated in harsher environments and could result from precipitation-driven differences in average resource availability or risk, or the cost of maintaining homeostasis under different precipitation regimes. The relationship between measured precipitation levels and GCs has not previously been examined in a phylogenetically controlled analysis, but environmental aridity (coded as "arid" or "not arid") was not retained in the top models of baseline GCs in passerine birds (Hau et al. 2010). The specific pathways through which precipitation may influence GC-fitness relationships will require additional targeted study; however, the general importance of precipitation as a selective factor has been demonstrated in a recent global analysis of selection differences across different precipitation regimes (Siepielski et al. 2017).

Although HPA activation is widely hypothesized to be an important mechanism for coping with unpredictable environments (Wingfield 2003, 2013a; Romero et al. 2009; Liebl and Martin 2012; Rubenstein et al. 2016), neither baseline nor stress-induced GCs were predicted by environmental variation. The relationship between short-term environmental variation and circulating GCs has not to our knowledge been tested across species, but environmental unpredictability appears to increase the strength of purifying selection on the GC receptor gene $(\mathrm{Nr} 3 \mathrm{cl}$ ) across African starling species (Hofmeister and Rubenstein 2016). It is conceivable that variation in other aspects of the HPA axis (or other phenotypic mediators) better predicts the capacity to cope with stressors than circulating baseline or stress-induced GCs (Wingfield 2013a; Hofmeister and Rubenstein 2016; Taff et al. 2018b). It is also possible that the metrics of environmental variation used here do not adequately capture true unpredictability or variation on the most relevant timescale. For example, intraseasonal variation may only loosely predict very short-term environmental variation (e.g., intra- or interday), which could be an important selective force. Nevertheless, intra- and interseasonal variation in temperature and precipitation have been used as metrics of environmental uncertainty in other large- 
scale analyses (e.g., Jetz and Rubenstein 2011). Annual variation in environmental characteristics also predicts variation in selection gradients and differentials on global scales (Siepielski et al. 2017).

The factor that best explained variation in stress-induced GCs, the interaction between lifetime reproductive opportunities and breeding status, was also a significant predictor within the omnibus model of baseline GCs; however, the nature of these relationships differed. Organisms with fewer lifetime opportunities to reproduce (which are expected to invest more in each reproductive attempt) had higher baseline GCs and lower stress-induced GCs during reproduction. These patterns are broadly consistent with the findings of a previous analysis of birds actively engaged in parental care (Bókony et al. 2009), which used a metric of brood value that incorporated both longevity and clutch size. A recent analysis, also in birds, which incorporated data from the breeding and nonbreeding seasons, found that clutch size positively predicted baseline but not stress-induced GC levels (Casagrande et al. 2018). The presence of this pattern at larger taxonomic scales, and in a data set that includes many measures from species and sexes that do not engage in parental care, suggests that general reproductive investment may be a particularly important driver of variation in GCs across populations and species. The opposing relationships seen between baseline and stressinduced GCs and lifetime reproductive opportunities also emphasize that the same selective pressures can have differing impacts on different components of HPA activity; this may result from a difference in the primary receptor type bound by baseline and stress-induced GCs (mineralocorticoid receptor vs. glucocorticoid receptor).

Neither longevity nor sociality were strong predictors of baseline GC levels (within the best-fit omnibus model) or stress-induced GCs. The second-ranked model of stressinduced GCs (which had a much poorer fit to the data than the top model) included an inverse relationship with the degree of sociality. This pattern is consistent with our prediction that lower stress-induced GCs will be favored in group-living species because of the elevated potential for social stress. However, a similar pattern could be generated by differences in risk: if group living reduces the risk of predation or other challenges, this could also favor lower stress-induced GCs. Future studies that take a finer-scale look at the relationships among GCs, relative risk, and the potential for social stress could shed light on how specific selective pressures related to sociality may impact GC levels across populations or species (Goymann and Wingfield 2004; Creel et al. 2013).

\section{Additional Findings: Sex, GC Type, and Phylogenetic Structure}

Sex was not a significant predictor of baseline GCs, but females had lower stress-induced GCs across tetrapods. Be- cause elevated GCs can be particularly costly to reproduction, this pattern could reflect a protective role of GC evolution reducing stress-induced levels more in the sex that tends to invest more in each reproductive attempt. Most previous phylogenetically informed analyses of steroid hormones have either included males only or averaged data from both sexes, but two analyses in birds support this hypothesis (Bókony et al. 2009; Casagrande et al. 2018). Our finding that sex does not predict baseline GCs across tetrapods is consistent with patterns observed in mammals (Haase et al. 2016) but not in birds (Casagrande et al. 2018).

GC type was not a significant predictor of either baseline or stress-induced GC levels. However, this analysis likely had limited power to detect these differences because a majority of the measures included in these analyses came from species that use corticosterone as the primary GC (birds, reptiles, amphibians, and most rodents). Although mammals are not underrepresented in the HormoneBase data set (Johnson et al. 2018), the strict filtering process implemented here excluded the majority of samples from free-living mammals, as well as fish, which were generally not collected under conditions conducive to obtaining true baseline samples. Future comparative work would benefit from prioritizing the sampling of free-living populations of these taxa in ways that enable true baseline levels to be detected.

The random effects of species, vertebrate group, and lab identity were significant. Both baseline and stress-induced GCs showed a strong phylogenetic signature (Pagel's $\lambda \geq 0.88$ ) thus, closely related species tend to have similar relationships between environment/life history and GC levels. This finding is generally consistent with previous comparative analyses within vertebrate groups (e.g., Jessop et al. 2013, 2016; Haase et al. 2016; Francis et al. 2018; but see Hau et al. 2010; Eikenaar et al. 2012; Garamszegi et al. 2018). Lab identity was included to account for the effects of variation in capture and sampling methods and assay technique (Fanson et al. 2017) on circulating GC levels. Unsurprisingly, lab identity was significant in both best-fit models, which is consistent with the only previous phylogenetic comparative analysis that included this factor (Bókony et al. 2009). However, its effect was substantially weaker than that of phylogenetic relatedness in both models.

\section{Comparative Analyses of Plastic Traits: Caveats and Future Directions}

Although comparative analyses of mean trait values across populations or species have provided significant insights into the evolution of behavior, physiology, and other labile traits, it is important to remember that such analyses cannot fully differentiate between evolved differences and environmentally driven plasticity in trait expression (e.g. Dupoué et al. 2018). GCs can markedly vary within as well 
as among individuals (Williams 2008; Cockrem 2013), although hormone levels do not appear to have greater withinpopulation variation than many other trait types (Miles et al. 2018). Despite this variation, GC levels are repeatable at both the level of individuals and that of populations (Garamszegi et al. 2018; Taff et al. 2018a), and numerous studies have shown evidence of evolved differences in GC levels (e.g., Satterlee and Johnson 1988; Pottinger and Carrick 1999; Baugh et al. 2012). Disentangling the extent to which hormonefitness relationships represent adaptive plasticity or are indicative of natural selection is a key challenge in evolutionary endocrinology (Bonier and Martin 2016). Large-scale comparative analyses such as this can be particularly fruitful for identifying and comparing putative selective pressures operating on endocrine traits, which can then be probed through an array of other approaches (Bonier and Martin 2016; Vitousek et al. 2018b).

Particularly promising future directions include using targeted experimental manipulations and selection experiments as well as comparisons of populations inhabiting different environments to explore the extent to which the factors identified here alter GC levels. As GC and life-history data accumulate, especially in undersampled taxonomic groups, future large-scale analyses will be important for testing the generality of patterns in GC variation. Similarly, the increasing prevalence of data on other components and modifiers of the HPA axis (e.g., negative feedback efficacy, corticosteroidbinding globulin levels, receptor distribution) — several of which have been linked with fitness in natural populations (e.g., Romero and Wikelski 2010; Patterson et al. 2014) will ultimately enable a much more comprehensive view of how endocrine function is shaped by selection. Finally, while phylogenetically informed comparisons of endocrine traits have thus far focused solely on population or species means, understanding how and why within- and amongindividual endocrine variation differs - across populations and species - could yield particularly important insights into the evolution of these important phenotypic mediators.

\section{Acknowledgments}

This contribution is dedicated to the memory of Rosemary Knapp, exemplary scientist, mentor, and friend. Rosemary was a member of the HormoneBase collaboration who sadly passed away shortly before the publication of this article.

We are grateful to all those whose hard work produced the GC measurements analyzed here and to the many people who assisted in compiling published data in HormoneBase, particularly Jennifer Uehling and Stefania Casagrande. Conor Taff provided helpful advice on the figures. M.N.V. was supported by the National Science Foundation, Division of Integrative Organismal Systems (NSF-IOS 1457251), and the Defense Advanced Research Projects Agency (DARPA D17AP00033). The views, opinions, and/or findings expressed are those of the authors and should not be interpreted as representing the official views or policies of the Department of Defense or the US government.

\section{Literature Cited}

Anderson, K. J., and W. Jetz. 2005. The broad-scale ecology of energy expenditure of endotherms: constraints on endotherm energetics. Ecologv Letters 8:310-318.

Andrews, R. M., and F. H. Pough. 1985. Metabolism of squamate reptiles: allometric and ecological relationships. Physiological Zoology 58:214-231.

Angelier, F., D. Costantini, P. Blévin, and O. Chastel. 2018. Do glucocorticoids mediate the link between environmental conditions and telomere dynamics in wild vertebrates? a review. General and Comparative Endocrinology 256:99-111.

Angelier, F., R. L. Holberton, and P. P. Marra. 2009. Does stress response predict return rate in a migratory bird species? a study of American redstarts and their non-breeding habitat. Proceedings of the Roval Societv B 276:3545-3551.

Angelier, F., and J. C. Wingfield. 2013. Importance of the glucocorticoid stress response in a changing world: theory, hypotheses and perspectives. General and Comparative Endocrinology 190:118128.

Atwell, J. W., G. C. Cardoso, D. J. Whittaker, T. D. Price, and E. D. Ketterson. 2014. Hormonal, behavioral, and life-history traits exhibit correlated shifts in relation to population establishment in a novel environment. American Naturalist 184:E147-E160.

Baugh, A. T., S. V. Schaper, M. Hau, J. F. Cockrem, P. de Goede, and K. van Oers. 2012. Corticosterone responses differ between lines of great tits (Parus major) selected for divergent personalities. General and Comparative Endocrinology 175:488-494.

Bininda-Emonds, O. R. P., M. Cardillo, K. E. Jones, R. D. E. MacPhee, R. M. D. Beck, R. Grenyer, S. A. Price, R. A. Vos, J. L. Gittleman, and A. Purvis. 2007. The delayed rise of present-day mammals. Nature 446:507-512.

Blas, J., G. R. Bortolotti, J. L. Tella, R. Baos, and T. A. Marchant. 2007. Stress response during development predicts fitness in a wild, long lived vertebrate. Proceedings of the National Academy of Sciences of the USA 104:8880-8884.

Bókony, V., Á. Z. Lendvai, A. Liker, F. Angelier, J. C. Wingfield, and O. Chastel. 2009. Stress response and the value of reproduction: are birds prudent parents? American Naturalist 173:589-598.

Bonier, F., and P. R. Martin. 2016. How can we estimate natural selection on endocrine traits? lessons from evolutionary biology. Proceedings of the Roval Societv B 283:20161887.

Bonier, F., P. R. Martin, I. T. Moore, and J. C. Wingfield. 2009a. Do baseline glucocorticoids predict fitness? Trends in Ecology and Evolution 24:634-642.

Bonier, F., I. T. Moore, P. R. Martin, and R. J. Robertson. 2009b. The relationship between fitness and baseline glucocorticoids in a passerine bird. General and Comparative Endocrinology 163:208-213.

Breuner, C. W., S. H. Patterson, and T. P. Hahn. 2008. In search of relationships between the acute adrenocortical response and fitness. General and Comparative Endocrinology 157:288-295. 
Cabezas, S., J. Blas, T. A. Marchant, and S. Moreno. 2007. Physiological stress levels predict survival probabilities in wild rabbits. Hormones and Behavior 51:313-320.

Casagrande, S., L. Z. Garamszegi, W. Goymann, J. Donald, C. D. Francis, M. J. Fuxjager, J. F. Husak, et al. 2018. Do seasonal glucocorticoid changes depend on reproductive investment? a comparative approach in birds. Integrative and Comparative Biology 58:739-750.

Cavigelli, S. A., and M. J. Caruso. 2015. Sex, social status and physiological stress in primates: the importance of social and glucocorticoid dynamics. Philosophical Transactions of the Roval Society B 370:20140103.

Clarke, A., P. Rothery, and N. J. B. Isaac. 2010. Scaling of basal metabolic rate with body mass and temperature in mammals. Lournal of Animal Ecology 79:610-619.

Cockrem, J. F. 2013. Individual variation in glucocorticoid stress responses in animals. General and Comparative Endocrinology 181:4558.

Costantini, D. 2011. On the measurement of circulating antioxidant capacity and the nightmare of uric acid. Methods in Ecology and Evolution 2:321-325.

Creel, S., B. Dantzer, W. Goymann, and D. R. Rubenstein. 2013. The ecology of stress: effects of the social environment. Functional Ecology 27:66-80.

Crespi, E. J., T. D. Williams, T. S. Jessop, and B. Delehanty. 2013. Life history and the ecology of stress: how do glucocorticoid hormones influence life-history variation in animals? Functional Ecology 27:93-106.

Dallman, M. F. 2005. Fast glucocorticoid actions on brain: back to the future. Frontiers in Neuroendocrinology 26:103-108.

Datson, N. A., M. C. Morsink, O. C. Meijer, and E. R. de Kloet. 2008. Central corticosteroid actions: search for gene targets. European Journal of Pharmacology 583:272-289.

Del Giudice, M., C. L. Buck, L. E. Chaby, B. M. Gormally, C. C. Taff, C. J. Thawley, M. N. Vitousek, and H. Wada. 2018. What is stress? a systems perspective. Integrative and Comparative Biology 58:10191032.

de Magalhaes, J. P. 2004. HAGR: the human ageing genomic resources. Nucleic Acids Research 33:D537-D543.

Downs, C. J., J. P. Hayes, and C. R. Tracy. 2008. Scaling metabolic rate with body mass and inverse body temperature: a test of the Arrhenius fractal supply model. Functional Ecology 22:239-244.

Dupoué, A., A. Rutschmann, J. F. Le Galliard, J. Clobert, P. Blaimont, B. Sinervo, D. B. Miles, C. Haussy, and S. Meylan. 2018. Reduction in baseline corticosterone secretion correlates with climate warming and drying across wild lizard populations. Iournal of Animal Ecology 87:1331-1341.

Eastman, J. M., L. J. Harmon, and D. C. Tank. 2013. Congruification: support for time scaling large phylogenetic trees. Methods in Ecology and Evolution 4:688-691.

Eikenaar, C., J. Husak, C. Escallón, and I. T. Moore. 2012. Variation in testosterone and corticosterone in amphibians and reptiles: relationships with latitude, elevation, and breeding season length. American Naturalist 180:642-654.

Fanson, K. V., Z. Németh, M. Ramenofsky, J. C. Wingfield, and K. L. Buchanan. 2017. Inter-laboratory variation in corticosterone measurement: implications for comparative ecological and evolutionary studies. Methods in Ecology and Evolution 8:1745-1754.

Francis, C., J. Donald, C. Downs, M. Fuxjager, W. Goymann, M. Hau, J. Husak, et al. 2018. Metabolic scaling of stress hormones in vertebrate animals. Integrative and Comparative Biology 58:729738.

Garamszegi, L. Z., J. Donald, C. Francis, M. Fuxjager, W. Goymann, M. Hau, J. Husak, et al. 2018. Phylogeny and diversification: levels of glucocorticoid hormones and speciation rate in birds. Integrative and Comparative Biology 58:763-776.

Garamszegi, L. Z., K. Hirschenhauser, V. Bókony, M. Eens, S. Hurtrez-Boussès, A. P. Møller, R. F. Oliveira, and J. C. Wingfield. 2008. Latitudinal distribution, migration, and testosterone levels in birds. American Naturalist 172:533-546.

Gessaman, J. A., and K. A. Nagy. 1988. Energy metabolism: errors in gas-exchange conversion factors. Physiological and Biochemical Zoology 61:507-513.

Goerlich, V. C., D. Nätt, M. Elfwing, B. Macdonald, and P. Jensen. 2012. Transgenerational effects of early experience on behavioral, hormonal and gene expression responses to acute stress in the precocial chicken. Hormones and Behavior 61:711-718.

Goolsby, E. W., J. Bruggeman, and C. Ané. 2017. Rphylopars: fast multivariate phylogenetic comparative methods for missing data and within-species variation. Methods in Ecology and Evolution 8:22-27.

Goymann, W., I. T. Moore, A. Scheuerlein, K. Hirschenhauser, A. Grafen, and J. C. Wingfield. 2004. Testosterone in tropical birds: effects of environmental and social factors. American Naturalist 164:327-334.

Goymann, W., and J. C. Wingfield. 2004. Allostatic load, social status and stress hormones: the costs of social status matter. Animal Behaviour 67:591-602.

Haase, C. G., A. K. Long, and J. F. Gillooly. 2016. Energetics of stress: linking plasma cortisol levels to metabolic rate in mammals. Biology Letters 12:20150867.

Hadfield, J. D. 2010. MCMC methods for multi-response generalized linear mixed models: the MCMCglmm R package. Journal of Statistical Software 33:1-22.

Harris, I., P. D. Jones, T. J. Osborn, and D. H. Lister. 2014. Updated high-resolution grids of monthly climatic observations - the CRU TS3.10 dataset. International Journal of Climatology 34:623-642.

Hau, M., R. E. Ricklefs, M. Wikelski, K. A. Lee, and J. D. Brawn. 2010. Corticosterone, testosterone and life-history strategies of birds. Proceedings of the Roval Societv B 277:3203-3212.

Haussmann, M. F., and N. M. Marchetto. 2010. Telomeres: linking stress and survival, ecology and evolution. Current Zoology 56:714727.

Hofmeister, N. R., and D. R. Rubenstein. 2016. Environmental variability and the evolution of the glucocorticoid receptor $(\mathrm{Nr} 3 \mathrm{cl})$ in African starlings. Ecology Letters 19:1219-1227.

Jaffe, A. L., G. J. Slater, and M. E. Alfaro. 2011. The evolution of island gigantism and body size variation in tortoises and turtles. Biology Letters 7:558-561.

Jenkins, B. R., M. N. Vitousek, J. K. Hubbard, and R. J. Safran. 2014 An experimental analysis of the heritability of variation in glucocorticoid concentrations in a wild avian population. Proceedings of the Roval Societv B 281:20141302.

Jessop, T. S., M. L. Lane, L. Teasdale, D. Stuart-Fox, R. S. Wilson, V. Careau, and I. T. Moore. 2016. Multiscale evaluation of thermal dependence in the glucocorticoid response of vertebrates. American Naturalist 188:342-356.

Jessop, T. S., R. Woodford, and M. R. E. Symonds. 2013. Macrostress: do large-scale ecological patterns exist in the glucocorticoid stress response of vertebrates? Functional Ecology 27:120-130. 
Jetz, W., and D. R. Rubenstein. 2011. Environmental uncertainty and the global biogeography of cooperative breeding in birds. Current Biology 21:72-78.

Jetz, W., G. H. Thomas, J. B. Joy, K. Hartmann, and A. O. Mooers. 2012. The global diversity of birds in space and time. Nature 491:444448.

Jimeno, B., M. Hau, and S. Verhulst. 2017. Strong association between corticosterone levels and temperature-dependent metabolic rate in individual zebra finches. Iournal of Experimental Biology 220:4426-4431.

Johnson, M., C. Francis, E. Miller, C. Downs, and M. Vitousek. 2018. Detecting bias in large-scale comparative analysis: methods for expanding the scope of hypothesis-testing with HormoneBase. Integrative and Comparative Biology 58:720-728.

Kitano, J., Y. Kawagishi, S. Mori, C. L. Peichel, T. Makino, M. Kawata, and M. Kusakabe. 2011. Divergence in sex steroid hormone signaling between sympatric species of Japanese threespine stickleback. PLoS ONE 6:e29253.

Krause, J. S., H. E. Chmura, J. H. Pérez, L. N. Quach, A. Asmus, K. R. Word, M. A. McGuigan, et al. 2016. Breeding on the leading edge of a northward range expansion: differences in morphology and the stress response in the Arctic Gambel's white-crowned sparrow. Oecologia 180:33-44.

Kumar, S., G. Stecher, M. Suleski, and S. B. Hedges. 2017. TimeTree: a resource for timelines, timetrees, and divergence times. $\mathrm{Molecu}-$ lar Biology and Evolution 34:1812-1819.

Landys, M. M., M. Ramenofsky, and J. C. Wingfield. 2006. Actions of glucocorticoids at a seasonal baseline as compared to stress-related levels in the regulation of periodic life processes. General and Comparative Endocrinology 148:132-149.

Lendvai, A. Z., V. Bokony, F. Angelier, O. Chastel, and D. Sol. 2013. Do smart birds stress less? an interspecific relationship between brain size and corticosterone levels. Proceedings of the Roval Societv B 280:20131734.

Liebl, A. L., and L. B. Martin. 2012. Exploratory behaviour and stressor hyper-responsiveness facilitate range expansion of an introduced songbird. Proceedings of the Roval Societv B 279:4375-4381.

Lupien, S. J., B. S. McEwen, M. R. Gunnar, and C. Heim. 2009. Effects of stress throughout the lifespan on the brain, behaviour and cognition. Nature Reviews Neuroscience 10:434-445.

McEwen, B. S., and J. C. Wingfield. 2003. The concept of allostasis in biology and biomedicine. Hormones and Behavior 43:2-15.

McNab, B. K. 1997. On the utility of uniformity in the definition of basal rate of metabolism. Physiological Zoology 70:718-720.

Miles, M., M. Vitousek, J. Husak, M. Johnson, L. Martin, C. Taff, C. Zimmer, M. B. Lovern, and M. J. Fuxjager. 2018. Standing variation and the capacity for change: are endocrine phenotypes more variable than other traits? Integrative and Comparative Biology $58: 751-762$.

Oliveira, B. F., V. A. São-Pedro, G. Santos-Barrera, C. Penone, and G. C. Costa. 2017. AmphiBIO, a global database for amphibian ecological traits. Scientific Data 4:170123.

O’Reilly, K. M., and J. C. Wingfield. 2001. Ecological factors underlying the adrenocortical response to capture stress in Arctic-breeding shorebirds. General and Comparative Endocrinology 124:1-11.

Ouyang, J. Q., P. Sharp, M. Quetting, and M. Hau. 2013. Endocrine phenotype, reproductive success and survival in the great tit, Parus major. Journal of Evolutionary Biology 26:1988-1998.

Ouyang, J. Q., P. J. Sharp, A. Dawson, M. Quetting, and M. Hau. 2011. Hormone levels predict individual differences in reproduc- tive success in a passerine bird. Proceedings of the Roval Society B 278:2537-2545

Patterson, S. H., T. P. Hahn, J. M. Cornelius, and C. W. Breuner. 2014. Natural selection and glucocorticoid physiology. Lournal of Evolutionary Biology 27:259-274.

Pottinger, T. G., and T. R. Carrick. 1999. Modification of the plasma cortisol response to stress in rainbow trout by selective breeding. General and Comparative Endocrinology 116:122-132.

Pyron, R. A., F. T. Burbrink, and J. J. Wiens. 2013. A phylogeny and revised classification of Squamata, including 4161 species of lizards and snakes. BMC Evolutionary Biology 13:93.

Pyron, R. A., and J. J. Wiens. 2011. A large-scale phylogeny of Amphibia including over 2800 species, and a revised classification of extant frogs, salamanders, and caecilians. Molecular Phylogenetics and Evolution 61:543-583.

Rodewald, P., ed. 2015. The Birds of North America. Cornell Lab of Ornithology, Ithaca, NY. https://birdsna.org.

Roelants, K., D. J. Gower, M. Wilkinson, S. P. Loader, S. D. Biju, K. Guillaume, L. Moriau, and F. Bossuyt. 2007. Global patterns of diversification in the history of modern amphibians. Proceedings of the National Academy of Sciences of the USA 104:887-892.

Romero, L. M. 2002. Seasonal changes in plasma glucocorticoid concentrations in free-living vertebrates. General and Comparative Endocrinology 128:1-24.

. 2004. Physiological stress in ecology: lessons from biomedical research. Trends in Ecology and Evolution 19:249-255.

Romero, L. M., C. M. Bauer, R. de Bruijn, and C. R. Lattin. 2017. Seasonal rhythms. Pages 421-427 in G. Fink, ed. Handbook of stress. Vol. 2. Stress: neuroendocrinology and neurobiology. Elsevier, London.

Romero, L. M., M. J. Dickens, and N. E. Cyr. 2009. The reactive scope model - a new model integrating homeostasis, allostasis, and stress. Hormones and Behavior 55:375-389.

Romero, L. M., and M. Wikelski. 2010. Stress physiology as a predictor of survival in Galapagos marine iguanas. Proceedings of the Roval Society B 277:3157-3162.

Rubenstein, D. R., H. Skolnik, A. Berrio, F. A. Champagne, S. Phelps, and J. Solomon. 2016. Sex-specific fitness effects of unpredictable early life conditions are associated with DNA methylation in the avian glucocorticoid receptor. Molecular Ecology 25:1714-1728.

Sapolsky, R. M., L. M. Romero, and A. U. Munck. 2000. How do glucocorticoids influence stress responses? integrating permissive, suppressive, stimulatory, and preparative actions. Endocrine Reviews 21:55-89.

Satterlee, D. G., and W. A. Johnson. 1988. Selection of Japanese quail for contrasting blood corticosterone response to immobilization. Poultry Science 67:25-32.

Schmidt-Nielsen, K. 1997. Animal physiology. 5th ed. Cambridge University Press, Cambridge.

Schoenle, L. A., C. Zimmer, and M. N. Vitousek. 2018. Understanding context dependence in glucocorticoid-fitness relationships: the role of the nature of the challenge, the intensity and frequency of stressors, and life history. Integrative and Comparative Biology 58:777-789.

Scholander, P. F., R. Hock, V. Walters, F. Johnson, and L. Irving. 1950. Heat regulation in some Arctic and tropical mammals and birds. Biological Bulletin 99:237-258.

Schultner, J., A. S. Kitaysky, G. W. Gabrielsen, S. A. Hatch, and C. Bech. 2013. Differential reproductive responses to stress reveal the role of life-history strategies within a species. Proceedings of the Roval Societv B 280:20132090. 
Siepielski, A. M., M. B. Morrissey, M. Buoro, S. M. Carlson, C. M. Caruso, S. M. Clegg, T. Coulson, et al. 2017. Precipitation drives global variation in natural selection. Science 355:959-962.

Stedman, J. M., K. K. Hallinger, D. W. Winkler, and M. N. Vitousek. 2017. Heritable variation in circulating glucocorticoids and endocrine flexibility in a free-living songbird. Journal of Evolutionary Biology 30:1724-1735.

Taff, C. C., L. A. Schoenle, and M. N. Vitousek. 2018a. The repeatability of glucocorticoids: a review and meta-analysis. General and Comparative Endocrinology 260:136-145.

Taff, C. C., C. Zimmer, and M. Vitousek. 2018b. Efficacy of negative feedback predicts recovery from acute physiological challenges. Biology Letters 14:20180131.

Uyeda, J. C., M. W. Pennell, E. T. Miller, R. Maia, and C. R. McClain. 2017. The evolution of energetic scaling across the vertebrate tree of life. American Naturalist 190:185-199.

Vera, F., R. Zenuto, and C. D. Antenucci. 2017. Expanding the actions of cortisol and corticosterone in wild vertebrates: a necessary step to overcome the emerging challenges. General and Comparative Endocrinology 246:337-353.

Vitousek, M. N., M. A. Johnson, J. W. Donald, C. D. Francis, M. J. Fuxjager, W. Goymann, M. Hau, et al. 2018a. HormoneBase, a population-level database of steroid hormone levels across vertebrates. Scientific Data 5:180097.

Vitousek, M. N., M. A. Johnson, C. J. Downs, E. T. Miller, L. B. Martin, C. D. Francis, J. W. Donald, et al. 2019. Data from: Macroevolutionary patterning in glucocorticoids suggests different selective pressures shape baseline and stress-induced levels. American Naturalist, Dryad Digital Repository, http://dx.doi.org/10.5061/dryad .th03671.

Vitousek, M., M. A. Johnson, and J. F. Husak. 2018b. Illuminating endocrine evolution: the power and potential of large-scale comparative analyses. Integrative and Comparative Biology 58:712719.

Vitousek, M. N., C. C. Taff, K. K. Hallinger, C. Zimmer, and D. W. Winkler. 2018c. Hormones and fitness: evidence for trade-offs in glucocorticoid regulation across contexts. Frontiers in Ecology and Evolution 6:1-14.
Weathers, W. W. 1979. Climatic adaptation in avian standard metabolic rate. Oecologia 42:81-89.

Welcker, J., J. R. Speakman, K. H. Elliott, S. A. Hatch, and A. S. Kitaysky. 2015. Resting and daily energy expenditures during reproduction are adjusted in opposite directions in free-living birds. Functional Ecology 29:250-258.

White, C. R., N. F. Phillips, and R. S. Seymour. 2006. The scaling and temperature dependence of vertebrate metabolism. Biology Letters 2:125-127.

White, C. R., and R. S. Seymour. 2003. Mammalian basal metabolic rate is proportional to body mass ${ }^{2 / 3}$. Proceedings of the National Academv of Sciences of the USA 100:4046-4049.

Williams, T. D. 2008. Individual variation in endocrine systems: moving beyond the "tyranny of the golden mean." Philosophical Transactions of the Roval Society B 363:1687-1698.

Wilson, A. J., D. Réale, M. N. Clements, M. M. Morrissey, E. Postma, C. A. Walling, L. E. B. Kruuk, and D. H. Nussey. 2009. An ecologist's guide to the animal model. Iournal of Animal Ecology 79:13-26.

Wingfield, J. C. 2003. Control of behavioural strategies for capricious environments. Animal Behaviour 66:807-816.

- 2013a. The comparative biology of environmental stress: behavioural endocrinology and variation in ability to cope with novel, changing environments. Animal Behaviour 85:1127-1133.

- 2013b. Ecological processes and the ecology of stress: the impacts of abiotic environmental factors. Functional Ecology 27:37-44.

Wingfield, J. C., D. L. Maney, C. W. Breuner, J. D. Jacobs, S. Lynn, M. Ramenofsky, and R. D. Richardson. 1998. Ecological bases of hormone-behavior interactions: the "emergency life history stage." American Zoologist 38:191-206.

Wingfield, J. C., and R. M. Sapolsky. 2003. Reproduction and resistance to stress: when and how. Journal of Neuroendocrinology $15: 711-724$.
Associate Editor: Alison M. Bell Editor: Daniel I. Bolnick 